\title{
Transoral Endoscopic Modified Radical Neck Dissection for Papillary Thyroid Carcinoma
}

\author{
Duy Quoc Ngo', Toan Duc Tran ${ }^{1}$, Duong The Le ${ }^{1}$, Quy Xuan Ngo', and Quang Van Le ${ }^{1,2}$ \\ ${ }^{1}$ Department of Head and Neck Surgery, Vietnam National Cancer Hospital, Thanh Tri District, Hanoi, Vietnam; ${ }^{2}$ Hanoi \\ Medical University, Dong Da District, Hanoi, Vietnam
}

\begin{abstract}
Background. Recently, transoral endoscopic thyroidectomy via the vestibular approach (TOETVA) has become popular worldwide. ${ }^{1-3}$ After controlling for the technique, the authors used the transoral endoscopic approach to modified radical neck dissection (MRND) for papillary thyroid carcinoma with clinically positive lymph nodes in the lateral compartments. To the best of their knowledge, the authors report the first case of TOETVA for MRND.
\end{abstract}

Patient. A 27-year-old woman had a diagnosis of cT1aN1bM0 right papillary thyroid carcinoma (metastatic to a small right level 4 lymph node). Therefore, total thyroidectomy, bilateral central neck dissection, and MRND of right levels 2, 3, and 4 were performed via the transoral endoscopic approach.

Methods. Total thyroidectomy and bilateral central lymph node dissections were performed based on the three-trocar Anuwong technique. ${ }^{4}$ Then, the fourth incision was made near the sixth teeth in the right oral vestibular area for insertion of the fourth 5-mm trocar, which was used to expose the lateral lymph compartment and to perform right MRND easily.

Results. The operation was completed successfully without conversion to open surgery. The total operative time was $170 \mathrm{~min}$, and the operating time for MRND was 55

Supplementary Information The online version contains supplementary material available at https://doi.org/10.1245/s10434020-09466-7.

(C) Society of Surgical Oncology 2021

First Received: 26 August 2020

Accepted: 25 November 2020;

Published Online: 18 January 2021

D. Q. $\mathrm{NgO}$

e-mail: duyyhn@gmail.com min. The numbers of harvested lymph nodes were 7 and 8 in the central and right lateral compartments, respectively. The numbers of metastatic lymph nodes were 2 and 1 in the central and lateral compartments, respectively. No major postoperative complications occurred.

Conclusion. Transoral endoscopic MRND of levels 2, 3, and 4 can be feasible and safe for highly selected patients.

DISCLOSURE There are no conflicts of interest.

\section{REFERENCES}

1. Russell JO, Sahli ZT, Shaear M, et al. Transoral thyroid and parathyroid surgery via the vestibular approach: a 2020 update. Gland Surg. 2020;9:409-16.

2. Quang VL, Duy QN, Toan DT, et al. Transoral endoscopic thyroidectomy vestibular approach: an initial experience in Vietnam. Surg Laparosc Endosc Percutan Tech. 2020;30:209-13.

3. Ngo DQ, Tran TD, Ngo QX, Van Le Q. Transoral endoscopic thyroidectomy via vestibular approach with 4 trocars: a new technique. Ear Nose Throat J. 2020. https://doi.org/10.1177/ 0145561320943358.

4. Anuwong A. Transoral endoscopic thyroidectomy vestibular approach: a series of the first 60 human cases. World J Surg. 2016;40:491-7.

Publisher's Note Springer Nature remains neutral with regard to jurisdictional claims in published maps and institutional affiliations. 